\title{
Efecto antiinflamatorio y antioxidante de los flavonoides de las hojas de Jungia rugosa Less (matico de puna) en un modelo experimental en ratas
}

\author{
Antiinflammatory and antioxidant effects of Jungia rugosa Less (matico de \\ puna) leaves' flavonoids in rats
}

\author{
Edwin Enciso ${ }^{1}$, Jorge Arroyo ${ }^{2}$ \\ 'Escuela de Posgrado, Facultad de Farmacia y Bioquímica, Universidad Nacional Mayor de San Marcos. Lima, Perú \\ ${ }^{2}$ Laboratorio de Farmacología, Facultad de Medicina, Universidad Nacional Mayor de San Marcos. Lima, Perú.
}

\begin{abstract}
Resumen
Objetivos: Evaluar la actividad antiinflamatoria y antioxidante de la fracción flavónica extraída de las hojas de Jungia rugosa Less. Diseño: Experimental. Lugar: Facultades de Medicina y Farmacia y Bioquímica, Universidad Nacional Mayor de San Marcos, Lima, Perú. Material biológico: Fracción flavónica extraído de las hojas de Jungia rugosa Less y ratas. Intervenciones: Las hojas de Jungia rugosa Less fueron recolectadas en el cerro Condorcunca, a $3500 \mathrm{msnm}$, distrito de Quinua, departamento de Ayacucho. La actividad antiinflamatoria fue evaluada in vivo usando el método de edema plantar inducido por carragenina y en sangre se cuantificó los niveles séricos de interleuquinas 1, 6 y proteína C reactiva (PCR); también, se indujo el granuloma, según Sedwicks, evaluándose por histopatología. La actividad antioxidante fue evaluada in vitro mediante la neutralización del radical 1,1-difenil-2-picril-hidrazilo (DPPH). Principales medidas de resultados: Actividad antiinflamatoria y antioxidante. Resultados: La inflamación disminuyó en $43,8 \%$, y los niveles de interleuquinas 1, 6 y PCR lo fueron en $80 \%, 90 \%$ y $78 \%$, respectivamente, al ser comparados con el control $(p<0,05)$, siendo el efecto dosis dependiente, y brindó un $97,7 \%$ de inhibición de radicales DPPH. Conclusión: Se ha demostrado que la fracción flavónica extraída de las hojas de Jungia rugosa Less es antiinflamatoria y antioxidante.

Palabras clave: Jungia rugosa Less, flavonoide, actividad antiinflamatoria, actividad antioxidante.

\section{Abstract}

Objectives: To determine anti-inflammatory and antioxidant activities of Jungia rugosa Less leaves flavones' fraction. Design: Experimental. Setting: Faculties of Medicine and Pharmacy and Biochemistry, National University of San Marcos, Lima, Peru. Biological material: Flavones fraction extracted from Jungia rugosa Less leaves and rats. Interventions: Jungia rugosa Less leaves collected in Condorcunca's hill at 3500 m.a.s.I., Quinua district, Ayacucho department. The anti-inflammatory activity was assessed in vivo in carrageenan-induced paw edema model and 1,6 interleukins serum levels and C reactive protein (CRP) were measured in blood; granuloma was induced according to Sedwicks and studied by histopathology. The antioxidant effect was investigated in vitro by 1,1diphenyl-2-picrylhydrazyl (DPPH) radical neutralization. Main outcome measures: Anti-inflammatory and antioxidant effects. Results: Inflammation reduced in $43,8 \%$ and 1,6 interleukins and CRP levels decreased respectively $80 \%, 90 \%$ and $78 \%$ compared to control, in dose-dependent effect $(p<0,05)$, with $97,7 \%$ DPPH radicals inhibition. Conclusions: Flavones fraction extracted from Jungia rugosa Less leaves is anti-inflammatory and antioxidant.
\end{abstract}

Key words: Jungia rugosa Less, flavonoid, anti-inflammatory and antioxidant activity.

\section{An Fac med. 2011;72(4):231-7}

\section{INTRODUCCIÓN}

La inflamación es la respuesta del tejido vivo vascularizado a la lesión; puede ser causada por agentes biológicos, físicos o químicos ${ }^{(1)}$. Existe liberación de sustancias mediadoras -bradiquinina, prostaglandina, histamina y sero- tonina-, que inducen permeabilidad vascular (2). Estas sustancias que se liberan en el proceso inflamatorio, denominadas 'sopa algogénica', actúan en las terminaciones nerviosas activando el segundo tipo de nociceptor (tipo C) y generan dolor ${ }^{(3)}$. La IL-1 permite la inducción de genes que codifican para la ciclooxigenasa tipo 2 (COX2), la fosfolipasa A tipo 2 (PLAT2) y el óxido nítrico sintetasa inducible (iNOS). Otras citoquinas, como IL-2, IL-6 e IL-8, contribuyen a la aparición de manifestaciones de respuesta inflamatoria ${ }^{(4)}$. 
La inflamación es una respuesta protectora, cuyo principal objetivo es librar al organismo del elemento causante del daño celular, como microbios y toxinas, y de las consecuencias de ese daño, con formación de células y tejidos necróticos. Sin la inflamación, las infecciones se diseminarían y las heridas nunca cicatrizarían. Por otro lado, la inflamación no curada adecuadamente es la base de las reacciones de hipersensibilidad y enfermedades crónicas, como la artritis reumatoide, la aterosclerosis y la fibrosis pulmonar ${ }^{(5)}$.

La región andina de nuestro país posee una variada flora y dentro de ella, muchas especies con reconocida actividad benéfica para la salud. Dentro de estas especies se encuentra Jungia rugosa Less 'matico de puna', una especie vegetal que crece en la región andina de nuestro país, cuyas hojas son utilizadas como desinflamante y cicatrizante ${ }^{(6)}$. Las plantas contienen flavonoides, compuestos polifenólicos con efectos antiinflamatorios, antimicrobianos, antivirales, antiulceroso, antioxidante, antihepatotóxico y antihipertensivo ${ }^{(7)}$. Inhiben gran variedad de enzimas, como la ciclooxigenasa, lipooxigenasa, NADPH oxidasa y xantina oxidasa, los radicales libres y reducen el estrés oxidativo ${ }^{(8-11)}$. Los flavonoides, polifenoles y el alfa tocoferol poseen capacidad antioxidante ${ }^{(12)}$.

En el presente trabajo se logró contribuir al acervo científico y etnofarmacológico de la planta medicinal en estudio, para lo cual se planteó los siguientes objetivos específicos: 1) Determinar la actividad antiinflamatoria y antioxidante de la fracción flavónica extraída de las hojas de Jungia rugosa Less 'matico de puna' en ratas con inducción de inflamación aguda y crónica; y, 2) Explicar el posible mecanismo de acción antiinflamatorio, al determinar los niveles de las interleuquinas 1 y 6 , proteína $C$ reactiva y la actividad antioxidante por comparación del efecto, haciendo uso de estándares farmacológicos con la fracción flavónica extraída de las hojas de Jungia rugosa Less 'matico de puna'.

\section{MÉTODOS}

Para aislar los flavonoides, primero se maceró las hojas secas molidas con etanol al $80 \%$, con doble extracción, evaporación a sequedad del extracto, desengrasado con éter de petróleo, con la finalidad de eliminar grasas, ceras, pigmentos y otros metabolitos que pudieran interferir con la extracción de los flavonoides. Se extrajo líquidolíquido con acetato de etilo, utilizando embudo de separación, para recuperar finalmente la fracción de acetato de etilo (fracción flavónica) y evaporarla a sequedad. Los flavonoides presentes en la fracción acetato de etilo, extraído de las hojas de Jungia rugosa Less 'matico de puna', fueron verificados con la reacción de Shinoda, por cromatografía en capa fina y por técnicas espectrales UV ${ }^{(13)}$.

La actividad antiinflamatoria fue evaluada por el método de edema de pata inducida por carragenina, según Winter ${ }^{(14)}$. Se utilizó 30 ratas Holtzmann procedentes del Instituto Nacional de Salud, machos de $220 \pm 20$ g. Los animales fueron aclimatados durante una semana, luego sometidos a ayuno con libre acceso de agua, 12 horas antes del inicio del ensayo, y distribuidos aleatoriamente en 6 grupos de 5 ratas, y tratados vía oral de la siguiente manera: a) grupo control: polisorbato de sodio al 3\%; b) grupos con estándares farmacológicos de ibuprofeno $120 \mathrm{mg} /$ $\mathrm{kg}$ y dexametasona $2 \mathrm{mg} / \mathrm{kg}$; c) grupos con fracción flavónica de 25, 50 y 100 $\mathrm{mg} / \mathrm{kg}$, correspondientemente.

Media hora después se inyectó 0,1 $\mathrm{mL}$ de carragenina al $1 \%$ en la aponeurosis subplantar de la pata derecha. El diámetro de la pata inyectada y la contralateral fueron determinados con el micrómetro digital a 0, 0,5, 1, 2, 3, 5 y 7 horas después de inducir la inflamación y aplicar los tratamientos; el edema fue expresado como el incremento del diámetro de la pata inflamada en $\mathrm{mm}$.

El segundo método empleado fue bolsa de aire en ratas, según Sedwick ${ }^{(15)}$. Los animales fueron aclimatados durante una semana, entre 21 y $25^{\circ} \mathrm{C}$ y 50 y
60\% de humedad, con 12 horas de luz y oscuridad. Se inyectó vía subcutánea $20 \mathrm{~mL}$ de aire en el área intracapsular del lomo, formándose una bolsa de aire de forma oval que se conservó por reinflación con $10 \mathrm{~mL}$ de aire a los 3 y 6 días. El sétimo día, los animales fueron distribuidos aleatoriamente en 6 grupos de 5 ratas y tratados vía oral como en el caso anterior. Tres horas después, se inyectó $2 \mathrm{~mL}$ de carragenina al $1 \%$ disuelta en solución salina, directamente en la bolsa; los animales fueron sacrificados después de 48 horas con una dosis letal de tiopental $(1000 \mathrm{mg} / \mathrm{kg})$. Se aplicó a la bolsa de aire una inyección de $5 \mathrm{~mL}$ de solución salina conteniendo 0,1\% de ácido etilendiaminotetraacético (EDTA) y luego se realizó una incisión pequeña en la pared de la bolsa, y el contenido de la bolsa de aire fue removido cuidadosamente usando una pipeta Pasteur estéril. Se obtuvo $3 \mathrm{~mL}$ de exudado, al cual se midió las proteínas totales, y se realizó estudio histopatológico del granuloma inducido por carragenina. La evaluación histopatológica, según Devi ${ }^{(16)}$, se realizó con trozos de piel conteniendo los granulomas, los cuales fueron lavados suavemente con solución salina, para remover la sangre y los detritos adheridos al tejido. Estos fueron fijados en solución de formol al $10 \%$, tamponado por 7 días. Posteriormente, se procedió a realizar cortes de $3 \mu$ de espesor con ayuda de un micrótomo, y se coloreó con hematoxilina y eosina. Después de la deshidratación y limpieza de las láminas, se efectuó observación microscópica, siendo las calificaciones ausencia de macrófagos (0), una forma con macrófagos $(+)$, macrófagos mas linfocitos $(++)$ y macrófagos modificados $(+++)$.

Para la determinación de interleuquinas 1 (IL-1) e interleuquinas 6 (IL-6) se empleó el método inmunoensayo de quimioluminescencia ${ }^{(17)}$, para lo cual los animales fueron aclimatados durante una semana, luego sometidos a ayuno con libre acceso de agua 12 horas antes del inicio del ensayo. Se les distribuyó aleatoriamente en 6 grupos de 5 ratas, tratados vía oral como los 
casos anteriores y media hora después se inyectó $0,1 \mathrm{~mL}$ de carragenina al 1\%, en la aponeurosis subplantar. Se repitió los tratamientos a las 3 y 5 horas; a las 7 horas, se tomó $3 \mathrm{~mL}$ de sangre por punción cardíaca, se separó el suero y se procedió a evaluar los niveles de IL-1, IL-6 y proteína C reactiva.

Para determinar los niveles de IL-1 e IL-6 se empleó la preuba inmunológica de electroquimioluminiscencia utilizando el inmunoanalizador Elecsys 2010, para lo cual se incubó $30 \mu \mathrm{L}$ de suero con un anticuerpo monoclonal biotinilado específico anti-IL-1 y anti-IL-6. Luego, tras añadir un anticuerpo monoclonal marcado con quelato de rutenio y micropartículas recubiertas de estreptavidina, los anticuerpos formaron con el antígeno de la muestra un complejo sándwich. La mezcla de reacción fue trasladada a la célula de lectura donde, por magnetismo, las micropartículas se fijaron temporalmente a la superficie del electrodo. Los elementos no fijados fueron eliminados posteriormente con el reactivo ProCell. Al aplicar una corriente eléctrica definida, se produjo una reacción quimioluminiscente, cuya emisión de luz se midió directamente con un fotomultiplicador. Para determinar los niveles de proteína $C$ reactiva, se utilizó los analizadores VITROS de bioquímica y el sistema integrado VITROS $5600^{(18)}$, para lo cual se le depositó en $10 \mu \mathrm{L}$ de suero, que se distribuyó uniformemente desde la capa difusora a las capas subyacentes. La PCR de la muestra se unió a las perlas de captura vinculadas a la $\mathrm{PC}$ y al anticuerpo anti-PCR marcado con peroxidasa de rábano picante, para formar un complejo insoluble en forma de sándwich en la primera incubación. La posterior adición a la lámina de $12 \mu \mathrm{L}$ de líquido de inmunolavado VITROS eliminó los materiales no fijados del área de lectura, a la vez que proporcionó el peróxido de hidrógeno necesario para la oxidación del leucoderivado mediada por la enzima. La densidad de reflexión del colorante fue medida después de la adición del líquido de inmunolavado VITROS, al final de la segunda incubación. Esta densidad de reflexión fue directamente proporcional a la concentración de PCR en la muestra. Para determinar si el lavado había sido adecuado, el colorante de detección de lavado fue leído a $540 \mathrm{~nm}$ inmediatamente después de la segunda incubación .

La actividad antioxidante se realizó mediante el método de neutralización del radical 1,1-difenil-2-picrilhidrazilo $(\mathrm{DPPH}){ }^{(19)}$, para lo cual se preparó solución metanólica de DPPH de $20 \mu \mathrm{g} / \mathrm{L}$, solución metanólica de la fracción flavónica de 10,50 y $100 \mu \mathrm{g} / \mathrm{mL}$, blanco con metanol:agua (2:1) para ajustar el espectrofotómetro a cero, blanco de muestra con $0,75 \mathrm{~mL}$ de muestra y 1,5 $\mathrm{mL}$ de metanol y patrón de referencia (estándar) con 1,5 mL de DPPH y 0,75 $\mathrm{mL}$ de agua destilada. Las muestras fueron tratadas con el reactivo DPPH, realizándose la lectura a $517 \mathrm{~nm}$.

Los datos fueron procesados utilizando el paquete estadístico SPSS (statistical package for social sciences), versión 17,0. Se consideró significativa una $\mathrm{p}<0,05$, con intervalo de confianza del 95\%. Se aplicó el análisis de varianza (Anova) a los valores obtenidos, al administrar los diferentes tratamientos. Se determinó la media y error estándar de los valores individuales obtenidos para los animales de cada grupo.

\section{RESULTADOS}

De $1 \mathrm{~kg}$ de hojas secas se obtuvo un rendimiento de la fracción flavónica de $11,5 \mathrm{~g}$, que representó un $1,15 \%$. Por otro lado, se cuantificó el contenido de flavonoides, obteniéndose un 99,9\% de pureza. Los flavonoides fueron verificados con la reacción de Shinoda, dando una coloración roja, indicando la presencia de flavonoides tipo flavona, lo cual fue corroborado por cromatografía en capa fina y por técnicas espectrales UV ${ }^{(13)}$.

Los grupos tratados con los estándares y la fracción flavónica mostraron diámetros promedio de inflamación menores al grupo control y a las 5 y 7 horas de tratamiento hubo mejor recuperación del proceso inflamatorio inducido en ratas, con valor $\mathrm{p}<0,05$ (figura 1).

En la figura 2 se observa la eficiencia antiinflamatoria dosis dependiente de $32,8 \%, 38,4 \%$ y $43,8 \%$, a las dosis de 25,50 y $100 \mathrm{mg} / \mathrm{kg}$, respectivamente, efecto próximo al ibuprofeno $(47,7 \%)$ y superior a dexametasona $(40,95 \%)$.

En las figuras 3, 4 y 5 se observa los niveles de interleuquina 1 (IL-1), interleuquina 6 (IL-6) y proteína $C$ reactiva (PCR), evaluados a las 7 horas de la administración de la carragenina. Se aprecia que el ibuprofeno no fue eficaz

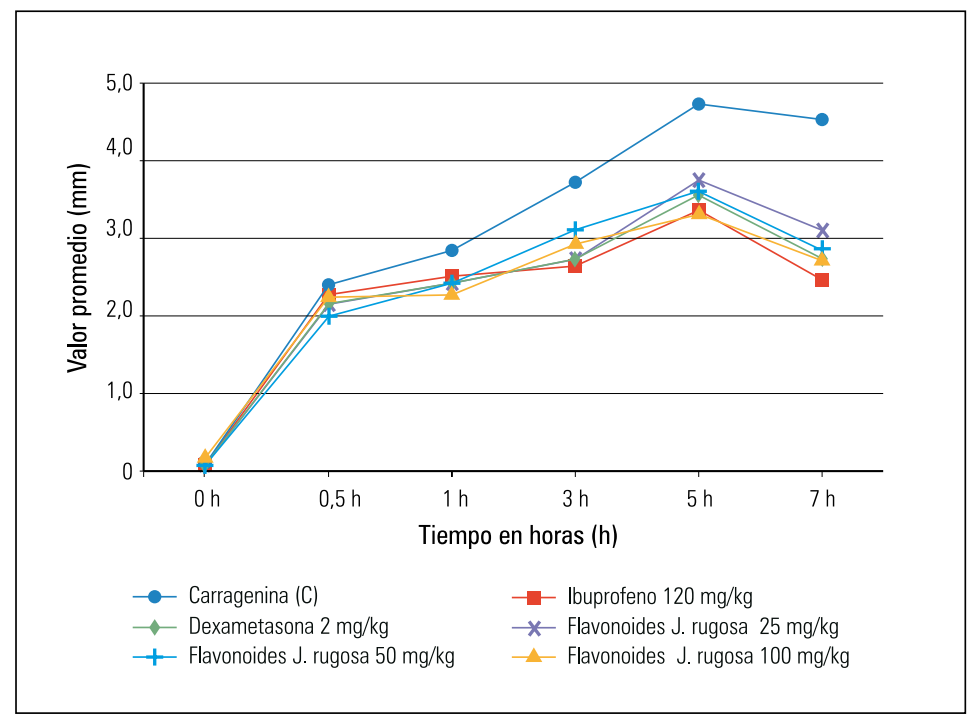

Figura 1. Diámetro de inflamación promedio al evaluar la actividad antiinflamatoria de la fracción flavónica extraída de las hojas de Jungia rugosa Less 'matico de puna'. 


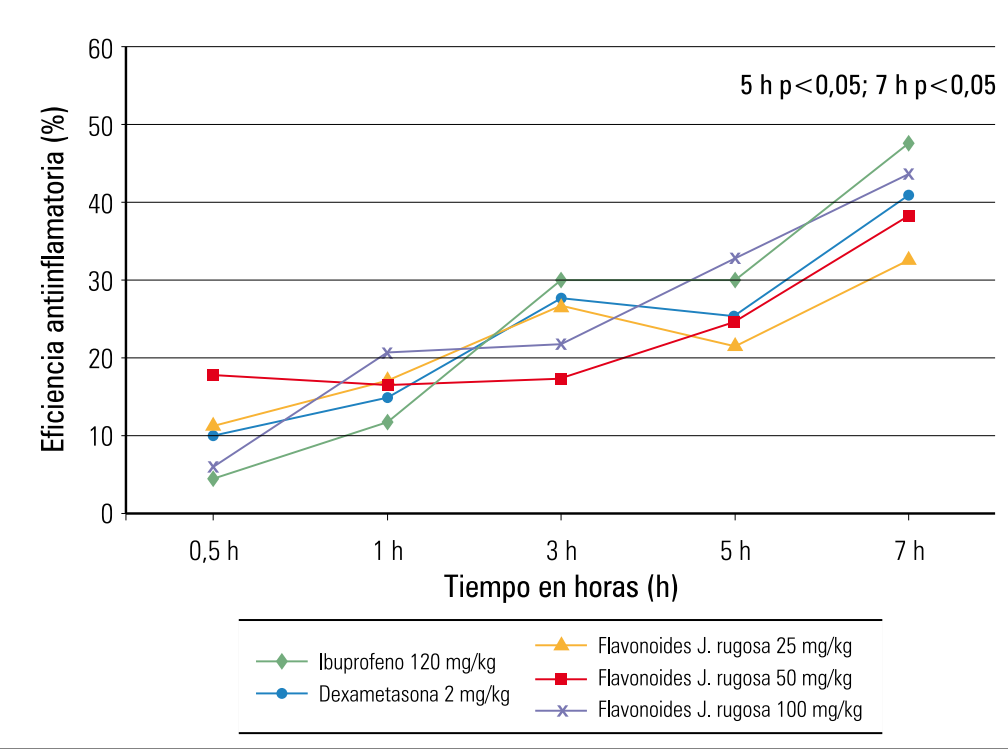

Figura 2. Porcentaje promedio de eficiencia antiinflamatoria al evaluar la actividad antiinflamatoria de la fracción flavónica extraída de las hojas de Jungia rugosa Less 'matico de puna'.

en inhibir los niveles de interleuquina, mientras que lo fue marcadamente con la dexametasona. Los tratamientos con la fracción flavónica disminuyeron muy por debajo del grupo control tratado con solución de polisorbato al $3 \%$ y el ibuprofeno. La fracción acetato de eti$\mathrm{lo}$, a las dosis de 50 y $100 \mathrm{mg} / \mathrm{kg}$, redujeron en forma similar a la dexametasona $(\mathrm{p}<0,05)$.

El estudio histopatológico mostró la existencia de daño leve y moderado de la piel de rata, con inducción de granuloma por carragenina, al evaluar la actividad antiinflamatoria de la fracción flavónica (figura $7(A-G)$ ).

En la figura 8 se indica que el efecto antioxidante in vitro fue mejor con la rutina, seguida por la fracción flavónica.

\section{DISCUSIÓN}

La evaluación de la actividad antiinflamatoria se ha realizado utilizando carragenina. Cabe resaltar que se ha preferido trabajar con carragenina y no con otros agentes irritantes, porque el edema que produce es menos modificado por factores ajenos a los propiamente característicos de la inflamación un incremento gradual del edema en el y, además, porque la actividad antiinflamatoria de esta prueba guarda correlación con la actividad antiinflamatoria en la clínica ${ }^{(20)}$. La carragenina es considerada agente flogística. En la rata, se ha descrito que durante las primeras tres horas después de la administración vía plantar de la carragenina tipo lambda se produce un comportamiento bifásico en la formación del edema plantar. En la primera fase, se registra transcurso de la primera hora, seguido de una segunda fase que dura hasta tres horas después de la administración de la carragenina, y que se caracteriza por un incremento abrupto del edema a partir de los 90 minutos ${ }^{(21)}$.

$\mathrm{Al}$ evaluar la actividad antiinflamatoria y la inhibición de IL-1, IL-6 y PCR de la fracción flavónica se demostró que, en ratas, inhibe en forma dosis dependiente el desarrollo de edema de la pata, a las 1, 3, 5 y 7 horas después de la inyección de carragenina. Una administración similar de flavonoides indujo una inhibición dependiente de la dosis de los niveles de IL-1, IL-6 y PCR. También, disminuyó los niveles proteínas en el exudado inflamatorio en las ratas (figura 6). Al evaluar la formación de granuloma por histopatología, se encontró que la fracción flavónica inhibió en forma dosis dependiente la formación de granuloma (figura 7). De acuerdo con los datos, el ibuprofeno fue mucho más efectivo en la inhibición de formación de edema plantar que en la infiltración de proteínas en el exudado y en la formación de granuloma, mientras que la dexametasona tuvo un comportamiento opuesto al ibuprofeno; la fracción flavónica se comportó con efecto similar al ibuprofeno en la inhibición del edema y en forma similar a la dexametasona en la inhibición de las IL-1, IL-6 y PCR. 


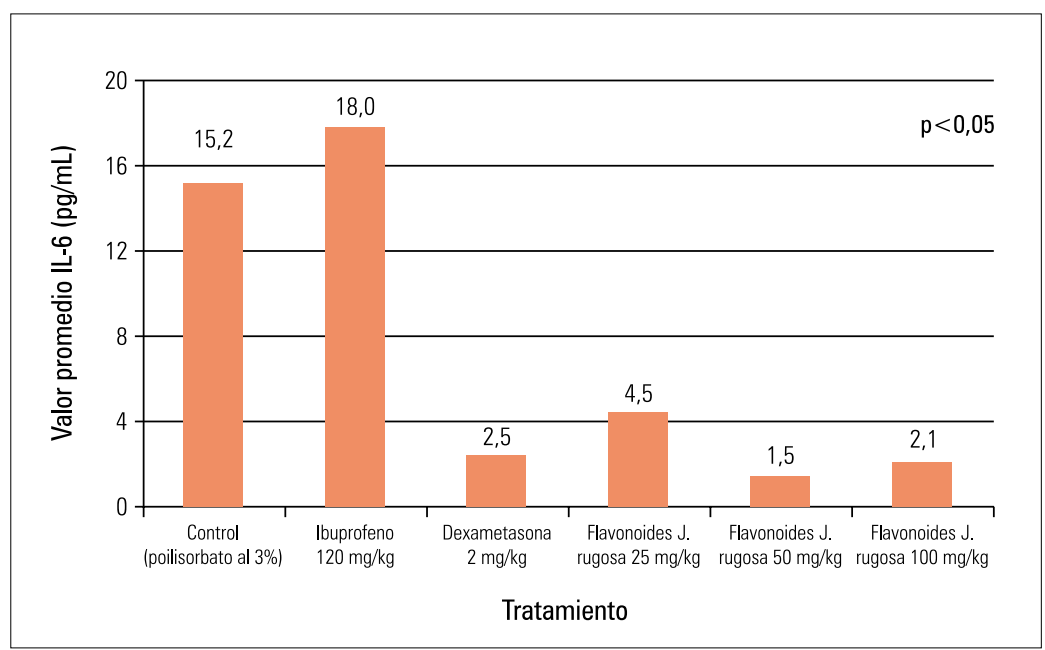

Figura 4. Niveles de interleuquina 6 (IL-6).

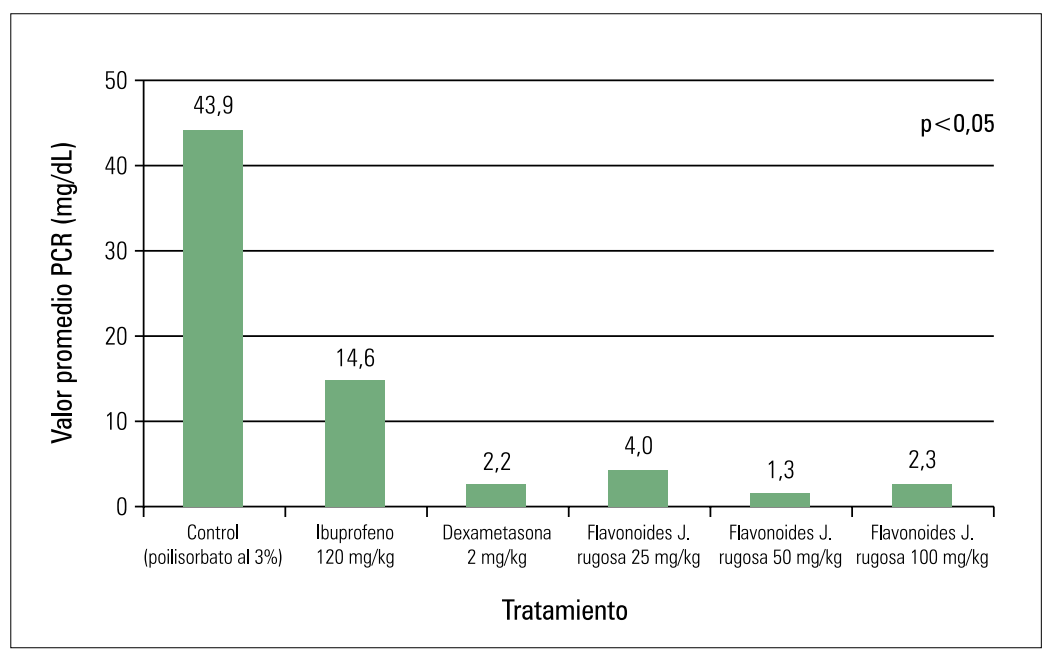

Figura 5. Niveles de proteina C reactiva (PCR).

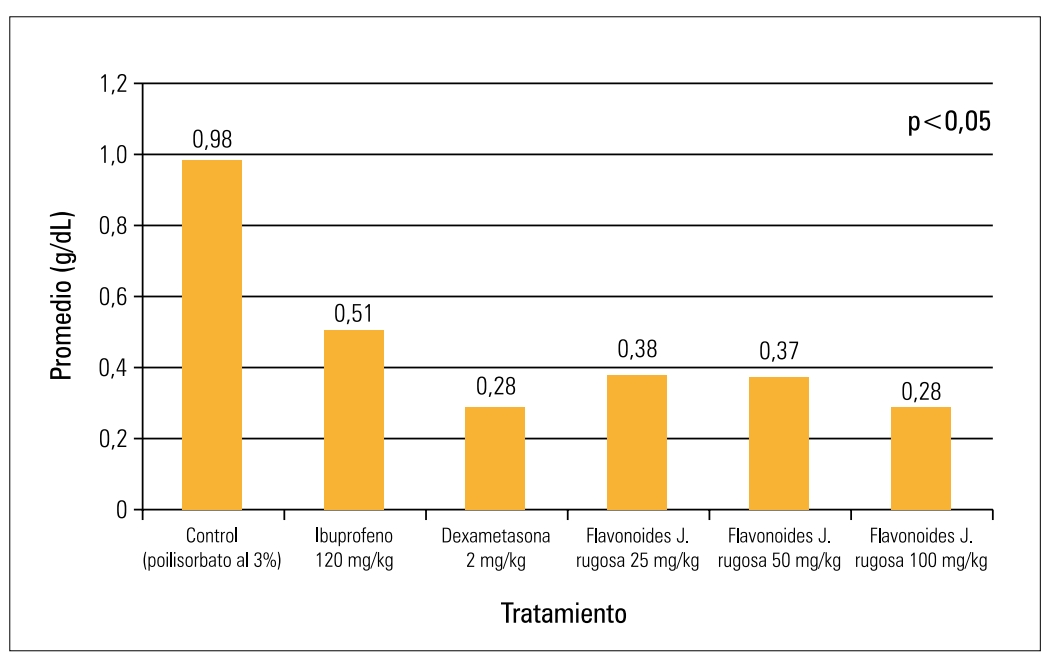

Figura 6 . Niveles de proteína en el exudado.
La acción antiinflamatoria que poseen muchos flavonoides se relaciona con la inhibición de diversas enzimas implicadas en el metabolismo del ácido araquidónico -como la ciclooxigenasa, lipooxigenasa, fosfato dinucleótido adenina nicotinamida (NADPH) oxidasa y xantina oxidasa-, y de radicales libres, y reducen el estrés oxidativo ${ }^{(8-11)}$; los flavonoides, polifenoles y alfa tocoferol poseen capacidad antioxidante ${ }^{(12)}$. In vitro, los flavonoides polihidroxilados actúan preferentemente por la vía de 5-lipooxigenasa, mientras que los menos hidroxilados inhiben fundamentalmente la vía de ciclooxigenasa. In vivo, sin embargo, parecen comportarse como inhibidores duales ${ }^{(22)}$. Esta diferencia de comportamiento, no exclusiva de flavonoides, se debe a la biotransformación que sufren en el organismo. Otros mecanismos implicados en la acción antiinflamatoria y en los cuales pueden intervenir los flavonoides son: inhibición de la liberación de histamina, inhibición de la migración celular (en el proceso inflamatorio los leucocitos se dirigen por quimiotactismo hacia el foco inflamatorio, donde son activados liberando eicosanoides y otros agentes proinflamatorios), acción antirradicalaria (actuando frente a los radicales libres que se originan en la inflamación), efecto protector vascular (contribuye a disminuir la exudación). Muchos de los flavonoides y fenoles cooperan en el efecto antiinflamatorio, pues una explicación posible sería la actividad inhibidora de la prostaglandina sintetasa, impidiendo por lo tanto la síntesis de prostaglandinas, componente responsable de la actividad inflamatoria ${ }^{(22)}$. Al estudiar la influencia de 22 flavonoides ${ }^{(23)}$ extraídos de plantas medicinales de España e India, en el metabolismo de ácido del araquidónico, demostraron que el grupo de flavonas y flavonoles inhibieron la 12 lipooxigenasa. Al evaluar la actividad antiinflamatoria en edema de oreja de ratón encontraron que la flavona, chry$\sin$ y apigenina se revelaron como buenos agentes inhibitorios, además de los flavonoles e isoflavonas ${ }^{(24)}$. Al evaluar la actividad antiinflamatoria in vivo 


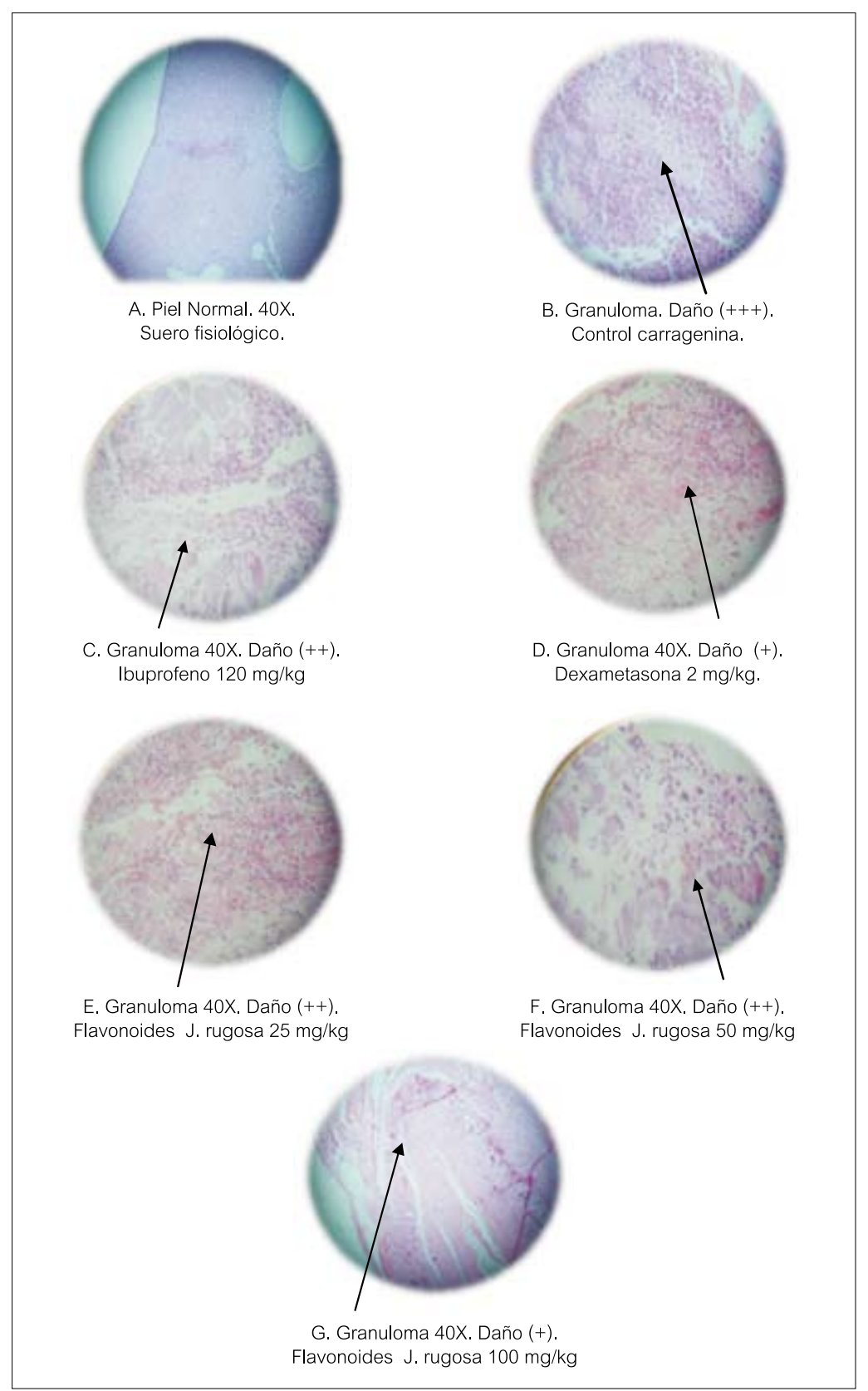

Figura 7 (A - G). Estudio histopatológico de la piel de rata con inducción de granuloma por carragenina, para evaluar la actividad antiinflamatoria de la fracción flavónica extraída de las hojas de Jungia rugosa Less "matico de puna".

Leyenda: $(-)$ = Ausencia de granuloma, $(+)=$ Daño leve, $(++)$ = Daño moderado, $(+++)=$ Daño severo.

por inducción de edema plantar con carragenina en ratas y la actividad antioxidante in vitro mediante la neutralización del radical DPPH del extracto metanólico de Jungia paniculata, determinaron que dicho extracto presenta buena actividad antiinflamatoria y alta actividad antioxidante ${ }^{(25)}$.
La IL-1 permite la inducción de genes que codifican para la ciclooxigenasa tipo 2 (COX2), la fosfolipasa A tipo 2 (PLAT2) y la óxido nítrico sintetasa inducible (iNOS). Otras citoquinas, como IL-2, IL-6 e IL-8, contribuyen a la aparición de manifestaciones de respuesta inflamatoria ${ }^{(2,4)}$. Las conse- cuencias biológicas de esta inducción se traducen en una franca respuesta inflamatoria. Por otra parte, los corticoides ejercen profundos efectos sobre las reacciones inmunitarias, inhibiendo la producción de interleuquinas IL-1 e IL-6 ${ }^{(26)}$. Explican que la interleuquina 1 (IL-1), el factor de necrosis del tumor alfa (TNF-alfa) y la interleuquina-6 (IL-6) modulan en la fase aguda de la inflamación la síntesis de proteínas del plasma, en hepatocitos humanos adultos. Solo la IL-6 estimula la síntesis de proteína $\mathrm{C}$ reactiva durante la inflamación. Estos datos sugieren que IL-6 tiene el papel crucial en la regulación de síntesis aguda de proteína de fase en los hepatocitos humanos. En resumen, se puede expresar que los flavonoides, al tener un comportamiento dual de inhibir la formación de prostaglandina E2 (PGE2) y leucotrieno B4 (LTB4), afectan el metabolismo del ácido araquidónico e inhiben la síntesis de interleuquina 1 (IL-1) y como consecuencia la interleuquina 6 (IL-6), lo cual a su vez afecta la síntesis de la proteína $\mathrm{C}$ reactiva (PCR).

La actividad antioxidante se evaluó utilizando el método de captación del radical 1,1-difenil-2-picrilhidrazilo (DPPH), observándose que los flavonoides presentes en la fracción flavónica mostraron actividad antioxidante dependiente de la concentración (figura 8), pero no manifestaron diferencias cuando se compara con la vitamina $\mathrm{C}$ y rutina, tal como se muestra en sus respectivas pruebas estadísticas, donde existe significancia en las concentraciones ensayadas, pero no con las sustancias de comparación; es decir, tienen una actividad antioxidante comparativamente similar a la vitamina $\mathrm{C}$ y rutina. De la actividad antioxidante de los flavonoides se sabe que las flavonas y flavonoles se muestran activos contra los radicales libres ${ }^{(27)}$. El 3',5-dihidroxi4',7-di metoxi flavona, 4',5,6,8-tetra metoxi-7-O-azúcar flavona y 3'-hidroxi-5,6,7-tri metoxiflavona que se encuentran en la fracción flavónica extraído de las hojas de Jungia rugosa Less, explican la alta actividad antioxidante 


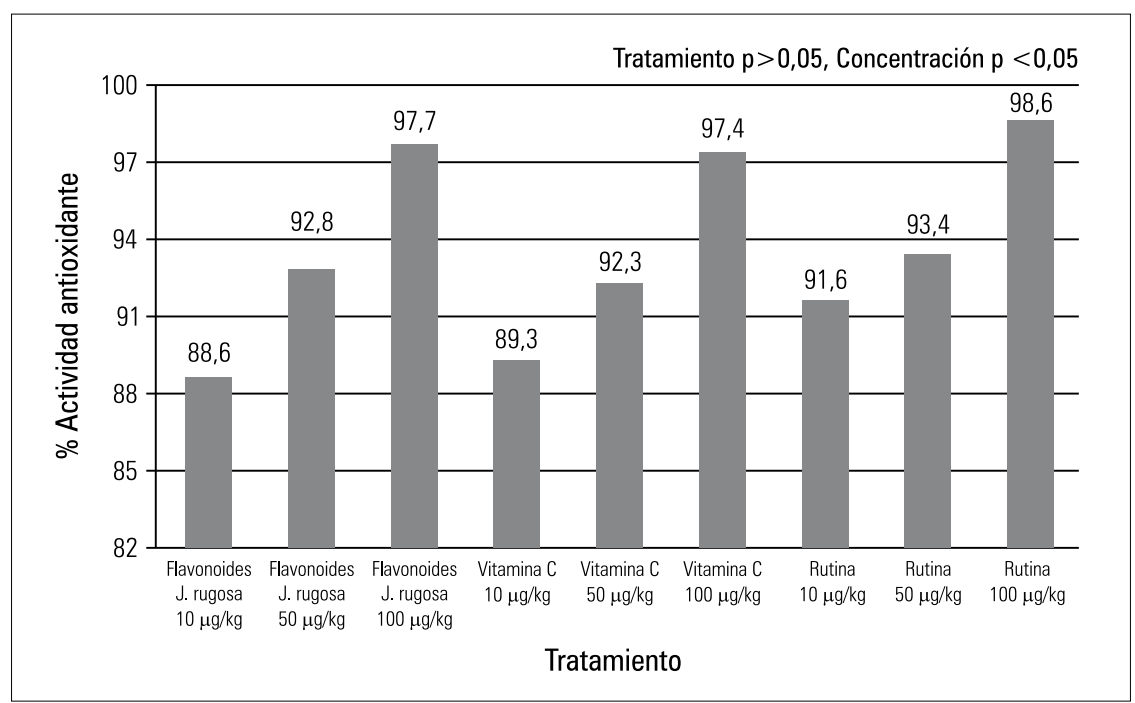

Figura 8. Actividad antioxidante in vitro de la fracción flavónica.

de los flavonoides semejante a los estándares utilizados.

Existe un consenso de que la actividad antioxidante de los flavonoides resulta de una combinación de sus propiedades quelantes de hierro y secuestradoras de radicales libres (RL) (28). Otros autores se refieren además a la inhibición de oxidasas, como la lipooxigenasa (LO), la ciclooxigenasa (COX), la mieloperoxidasa (MPO), la NADPH oxidasa y la xantina oxidasa $(\mathrm{XO}){ }^{(29)}$, evitando la generación de especies reactivas del oxígeno (ERO) in vivo, así como de hidroperóxidos orgánicos. Por otra parte, se ha podido conocer que también inhiben enzimas involucradas indirectamente en los procesos oxidativos, como la fosfolipasa A2 (FLA2) (30), al mismo tiempo que estimulan otras con reconocidas propiedades antioxidantes, la catalasa (CAT) y la superóxido dismutasa (SOD) ${ }^{(31)}$. De esta forma, los flavonoides interfieren en las reacciones de propagación de radicales libres y en la formación del radical en sí ${ }^{(32)}$.

\section{REFERENCIAS BIBLIOGRÁFICAS}

1. Coleman J. Nitric oxide in immunity and inflammation. Int Immunopharmacol. 2001;1(8):1397-406.

2. Mitchell R, Kumar V, Abbas A, Fausto N. Compendio de Robbins y Cotran: Patologia estructural y funcional. $7^{\text {a }}$. Edición. Madrid, España: Ed. Elsevier España S.A. 2007:30-57.
3. Katzung B, Masters S, Trevor A. Farmacologia básica y clínica. $11^{a}$ edición. China: Ed. McGraw-Hill. Interamericana. 2010:439-50.

4. Goodman y Gilman. Las bases farmacológicas de la terapéutica. 9a . Edición. México: Ed. McGraw-Hill. Interamericana. 1996:661-9.

5. Licastro F, Candore G, Lio D, Porcellini E, ColonnaRomano G, Franceschi C, Caruso C. Innate immunity and inflammation in ageing: a key for understanding age-related diseases. Immun Ageing. 2005;2:8.

6. De la Cruz J, Aucasime L, Ramírez A. Plantas medicinales alto-andinas de las zonas de Ayacucho - Huancavelica. Ayacucho, 2006:25-7.

7. Rathee P, Chaudhary H, Rathee S, Rathee D, Kumar $\mathrm{V}$, Kohli K. Mechanism of action of flavonoids as anti-inflammatory agents: inflammation \& allergy. Drug Targets. 2009;8(3):229-35.

8. Middleton E, Kanndasamy C, Theoharides TC. The effects of plant flavonoids on mammalian cells: implication for inflammation, heart disease and cancer. Pharmacol Rev. 2000;52(4):673-751.

9. De Groot H, Raven $\mathrm{C}$. Tissue injury by reactive oxygen species and the protective effects of flavonoids. Fundam Clin Pharmacol. 1998;12:249-55. neous generation of nitric oxide and superoxide by inflammatory cells in rats. Free Rad Biol Med. 1995;18(5):869-75.

11. Garcia L, Rojo D, Garcia LV, Hernández M. Plantas con propiedades antiinflamatorias. Centro de Investigaciones Biomédicas "Victoria de Girón" Rev Cubana Invest Biomed. 2002;21(3):214-6.

12. Hassing A, Liang WX, Schwabl H, Stampfli K. Flavonoids and tannins: plant-based antioxidants with vitamin character. Med Hypotheses. 1999;52(5):479-81.

13. Lock de Ugaz. Investigación Fitoquímica. Métodos en el Estudio de los Productos Naturales. Segunda Edición. Fondo Editorial de la Pontifica Universidad Católica del Perú. 1994:114-33.

14. Arroyo J, Rojas J, Chenguayen J. Manual de Modelos Experimentales de Farmacología. Primera Edición. Lima, Perú: Editorial Asdimor. 2004:59-62.

15. Flores D, Cervantes J, Munares O. Modelos animales de enfermedad: Ensayos farmacológicos in vivo. Primera edición. Lima. 2005:167-78.
10. Ródenas J, Mitjavila MT, Carbonell T. Simulta-
16. Devi CJ, Narayan S, Vani G, Shimala. Gastroprotective effect of terminalia arjuna backon diclofenac sodium induced gastric ulcer. Chem Biol Interact. 2007;167(1):71-83.

17. COBAS. Inmunoensayo de electroquimioluminiscencia para la determinación de interleuquinas 1 (IL-1) e interleuquinas 6 (IL-6). Elecsys. 2010:1-4.

18. VITROS Chemistry Products. Determinación cuantitativa de proteina $C$ reactiva (PCR) en suero y plasma utilizando los analizadores VITROS 250. 2010:1-4.

19. Chávez R, Plaza A, Lock O. Antioxidantes de origen vegetal. Rev Química. 1996;10(1):71-101.

20. CYTED. Programa Iberoamericano de Ciencia y Tecnologia para el Desarrollo. Manual de técnicas de investigación. Proyecto X-I Búsqueda de principios activos en plantas medicinales. 1995:81-3.

21. Vinegar, Schreiber, H. Biphasic development of carrageen in edema in rats. J Pharmacol Exp Ther. 1969;166(1):99-103.

22. Ferrándiz ML, Alcaraz MJ. Anti-inflammatory activity and inhibition of arachidonic acid metabolism by flavonoids. Agents Actions. 1991;32:283-8.

23. Ferrándiz ML, Nair AG, Alcaraz MJ. Inhibition of sheep platelet arachidonate metabolism by flavonoids from Spanish and Indian medicinal herbs. Pharmazie.1990;45(3):206-8.

24. Kim HK, Namgoong SY, Kim HP. Anti-inflammatory activity of flavonoids: mouse ear edema inhibition. Arch Pharmacol Res. 2008;16(1):18-24.

25. Casado R, Land A, Calvo J, Del Carmen Terencio M, Calvo MI. Anti-inflammatory and antioxidant activities of Jungia paniculata. Pharm Biol. 2010;48(8):897-905.

26. Castell JV, Gómez-Lechón MJ, David M, Andus T, Geiger T, Trullenque R, Fabra R, Heinrich PC. Interleukin-6 is the major regulator of acute phase protein synthesis in adult human hepatocytes. FEBS Lett. 1989;242(2):237-9.

27. Bruneton J. Plantas Medicinales. Fitoquímica y Farmacognosia. Zaragoza: Editorial Acribia. 2001:306-39.

28. Böhm H, Boeing H, Hempel J, Raab B, Kroke AZ. Flavonols, flavone and anthocyanins as natural antioxidants of food and their possible role in the prevention of chronic diseases. Z Ernährungswiss. 1998;37(2):147-63.

29. Groot H de, Rauen U. Tissue injury by reactive oxygen species and the protective effects of flavonoids. Fundam Clin Pharmacol. 1998;12(3):249-55.

30. Lindahl M, Tagesson C. Flavonoids as phospholipase A2 inhibitors: importance of their structure for selective inhibition of group II phospholipase A2. Inflammation. 1997;21(3):347-56.

31. Sudheesh S, Sandhya C, Sarah KA, Vijayalakshmi NR. Antioxidant activity of flavonoids from Solanum melongena. Phytother Res. 1999;13(5):393-6.

32. Van Acquire SA, Van den Berg DJ, Tromp MN, Griffioen DH, Van Bennekom WP, Van der Vijgh WJ, et al. Structural aspects of antioxidant activity of flavonoids. Free Radic Biol Med. 1996;20(3):331-42.

Artículo recibido el 16 de julio de 2011 y aceptado para publicación el 19 de setiembre de 2011.

Fuentes de financiamiento: Propias.

Conflictos de intereses: Los autores expresan no tener algún conflicto de interés.

Correspondencia:

Dr. Edwin Carlos Enciso Roca

Facultad de Farmacia y Bioquímica

Correo-e: encisoqf@hotmail.com. 